\title{
2 A Gross-National Analysis of Women Graduates with Tertiary Degrees in Science, Technology, Engineering, and Math, 1998-2018
}

\section{Commonalties and Variations}

\author{
Seungah S. Lee, Christine Min Wotipka and \\ Francisco O. Ramirez
}

Much of the growing comparative scholarship on women and higher education focuses on women and the fields of science, technology, engineering, and math (STEM). This literature has mostly addressed issues of access and examined patterns of women's enrollments in STEM relative to those of men (Charles, 2011). What has motivated this literature is the sense that there are higher monetary payoffs for women who enter these fields than non-STEM fields, as well as higher entry barriers. This motivation is grounded in a women's rights perspective. The literature is further motivated by the belief that national economic development is fostered by innovations triggered by STEM. This motivation is rooted in a human capital perspective. From both perspectives, more women in STEM is a desideratum, benefiting women and their societies.

In what follows, we briefly review the literature and studies that address women in STEM. However, our paper focuses on graduation numbers, not merely enrollment patterns, as both perspectives ultimately are concerned with outcomes better captured via data on graduation patterns. The women's rights perspective has generated the "chilly climate" idea that can be more rigorously examined through an inspection of graduation patterns. The human capital perspective with its emphasis on expanding human resources is also better assessed with data on outcomes. Both perspectives are evident in many policy reports that highlight the importance of having more women in STEM. The European Technology Assessment Network (2000), for example, champions women in STEM, emphasizing women both as rights bearers and as contributors to human capital. Our chapter explores cross-national trends in STEM degree graduates at the tertiary level ${ }^{1}$ from 1998 to 2018 for 143 countries.

The first part of this chapter examines women in STEM cross-national studies. These studies reveal both some common change patterns as well as variations. Next, we reflect on the STEM for national economic development literature. Lastly, we provide evidence on interrelated but different questions: 


\section{Seungah S. Lee et al.}

(a) What percentage of women graduates obtained STEM degrees, and how does this compare to men graduates with STEM degrees? (b) What percentage of STEM graduates are women relative to men?

We have learned from prior studies that there are gender gaps, with men continuing to dominate in STEM fields, which is an international trend (Charles \& Bradley, 2009). The issue though is whether these gaps persist over time, globally, and across levels of economic development. Or, alternatively, have there been changes, and have these changes been in the direction of greater gender equality? Earlier modernization-inspired studies implied that changes would be more evident in more developed countries (Boserup, 1981). However, recent research suggests otherwise (Charles \& Bradley, 2009). We directly address this question by comparing changes in countries that vary with respect to their level of development.

\section{Women and STEM}

Throughout the 20th century, women's social movements have pressed to change the status of women, from mainly wives and mothers to citizens and persons (Berkovitch, 1999). These social movements led to the global acquisition of the franchise (Ramirez, et al., 1997) and to other legal and social changes in the direction of greater equality in some societal domains (Dorius \& Firebaugh, 2010). In the realm of higher education, the impact of women's movements was neither anticipated nor well understood. As higher education greatly expanded in the post-World War II era (Schofer \& Meyer, 2005), women's share of higher education increased. Between 1970 and 2010, this increase was evident across all the regions of the world, with women's share at $50 \%$ or more in every region except Sub-Sahara Africa. In the latter, however, women's share tripled, from a little over $10 \%$ in 1970 to over $30 \%$ by 2010 (Ramirez \& Kwak, 2015). The worldwide expansion of higher education is in good part driven by the growing presence of women therein (Bradley \& Ramirez, 1996).

However, some scholars were quick to correctly point out that much of this increase likely took place in fields like the humanities, social sciences, and education, and not in STEM (Bradley, 2000; Kelly, 1989). Expanded participation by women in higher education may be less consequential for women if they entered fields of study that do not yield the higher occupational and income payoffs associated with STEM. Furthermore, from a national policy perspective increasingly focused on STEM as a crucial launching pad for economic development, expanded participation by women outside STEM also could be less significant.

These reservations led some researchers to directly examine women's share of STEM in higher education. Several findings emerge from these studies: first, as expected, women's share of STEM enrollments was lower between 1972 and 1992 in Ramirez and Wotipka's study (2001) and between 1970 and 2010 in Ramirez and Kwak's study (2015). STEM has been and continues to be more inhabited by men. 
A second finding, however, was not expected: women's share of STEM increased over time. Perhaps even more surprising, is that the increase is found in every region of the world (Ramirez \& Kwak, 2015). In the 1970s, women's share was between 10 and $20 \%$, but by 2010 the share was between 30 and $40 \%$. The trend, albeit slowly, is moving in the direction of greater gender equality. This trend may reflect earlier developments in lower levels of schooling. Over time, girls' scores in math and science international tests have improved, narrowing the gender achievement gap in these domains (Baker \& Jones, 1993; Wiseman, 2008). Furthermore, math educators have increasingly advocated for reforms in math pedagogy and curricula with the goal of undercutting the gender gap (Boaler, 1997). The gender gap may be declining, but it is garnering more global attention than in earlier eras.

Bear in mind that these comparative studies examined enrollments. In some systems of higher education (for example, the United States), students can readily change majors, thereby shifting from STEM to other disciplines. This chapter focuses on graduation patterns for all tertiary levels precisely because it is a more rigorous measure of the degree to which STEM has opened or failed to open to women. That is, one can imagine increased enrollments due to greater demand and less barriers to entry, but nevertheless more obstacles to degree completion that result in graduation rates patterns that differ from enrollment patterns. Women have shown to be particularly vulnerable to the "chilly climate" in STEM that leads to a "leaky pipeline" (Blickenstaff, 2005). In fact, studies have found that women are more likely to leave the STEM pipeline at various milestones for reasons such as lower mathematical confidence (Ellis, et al., 2016), lack of women role models (Shapiro \& Sax, 2011), perception of major, and negative feedback in the form of relatively low grades (Kugler, et al., 2017).

Before we examine change in STEM graduation patterns, we also review the literature on STEM for national economic development. First, we examine the global, regional, and national policy discourse emphasizing the centrality of science, technology, and engineering in the pursuit of national economic development. Next, we review studies that seek to empirically ascertain the relationship between STEM and national economic development. In both instances, we consider references to the role of women in this development endeavor. Lastly, we raise and seek to answer our main research question: Given so much interest in STEM, what does the STEM share of higher education degree holders look like?

\section{STEM for National Economic Development}

The United Nation's (UN) Sustainable Development Goals adopted in 2015 focus on three dimensions of development - economic, social, and environmental. Key to each aspect is the role played by the STEM fields as well as by women. As affirmation of the combined importance of STEM and women, the UN declared February 11 of each year the International Day of Women 
and Girls in Science. In doing so, the UN recognized that the underrepresentation of women in STEM was not only a matter of women's economic and social rights but also needed to be rectified for the good of countries and the global community (Wotipka \& Ramirez, 2003).

This global push for STEM resonates with many regions and countries, as manifested in their calls for greater investments in STEM. For example, the European Union's Horizon 2020, the largest research and innovation program of its kind, aims to drive economic growth and create jobs. Science education, especially for girls, is regarded as key to these efforts. Similarly, the African Union's Agenda 2063 sees science, technology, and innovation as critical to its inclusive growth and sustainable development (African Union, 2020). In East Asia, although students perform very well on the OECD's Program for International Student Assessment (PISA), including science and mathematical knowledge in real-world contexts and creativity, efforts are underway to utilize more student-centered learning approaches, which may help attract more girls and women to STEM fields in a region where their representation is lacking (Huyer, 2015). Arab States' Strategy for Science, Technology and Innovation calls for science education and universities and research and development to be expanded (Zou'bi, et al., 2015). We also find country level initiatives that display a positive reception to the global science for development agenda and women in science as a feature of this agenda.

This global push has been propped up by the growth of international testing regimes with math and science achievement garnering the most attention in policy circles and in the mass media. In the US, the publication of $A$ Nation at Risk (NCEE, 1983) boldly claimed that the lower standing of American students in the Second International Mathematics Study (SIMS) foreshadowed the decline of the country on the world stage. Earlier concerns in the Cold War era were more attuned to geopolitical and military competition, but the Nation at Risk fear was mostly framed in economic terms with Japan (and later the so-called Asian Tigers as the rising competitors). The same fear underlies Rising above the Gathering Storm (Committee on Prospering in the Global Economy of the 21st Century, 2007) with this report specifically focused on STEM in higher education. Not surprisingly, this report also points to the need for more women in STEM. Appraising the report, Vest (2010) stresses the need to train more STEM teachers, support more science and engineering research, train more higher education STEM students, and provide more incentives for innovations to avoid a "category 5" storm.

Underlying these global, regional, and national policy prescriptions is the belief in a direct relationship between STEM education and national economic development. This has led to a greater focus on science and math achievement, including efforts to improve countries' standings on international tests (Ritz \& Fan, 2015). The evidence on whether higher international test scores is associated with economic development is mixed. Hanushek and Kimko (2000) find a positive association while other researchers conclude that the association is mostly an "Asian Tigers" effect (Ramirez, et al., 2006). A review of empirical 
research on the link between science education and economic development finds that the evidence is inconclusive (Drori, 2000). However, there is evidence of a positive association between the level of tertiary science and engineering enrollments and economic development. Other indictors of national scientific activity (for example, numbers of publications or citations) fail to positively influence economic development (Ramirez \& Lee, 1995; Schofer, et al., 2000).

So, what impact, if any, do global, regional, and national STEM for development pressures have on the growth of STEM? Focusing on enrollments, Wotipka and Ramirez (2003) find that while STEM enrollments grow in absolute terms, relative to the rest of higher education, one does not see growth over time. A similar finding is reported in Ramirez and Kwak (2015). What this means is that the global expansion of higher education is not driven by STEM. Other sectors of higher education grow more extensively than STEM does. Of course, we are here dealing with a global average, and there is variation across regions and countries. As we report later in our findings, the Middle East and North Africa region, for example, shows small growth in STEM enrollments between 1998 and 2018. Likewise, sub-Saharan Africa shows minimal growth in STEM graduates between 1998 and 2018. But we see declines in other regions of the world such as Asia, Latin America, North America, and Western Europe. In fact, the overall STEM share of higher education graduates decreased from $33.47 \%$ in 1998 to $22.56 \% 20$ years later in 2018 .

Despite increased efforts to bring more students into STEM fields of study, we do not observe a spike in the STEM share of higher educational enrollments or graduates. One could argue that where there was less push for STEM, one might actually find sharp declines. In fact, only in Eastern Europe does one detect a sharp decline in STEM enrollments between 1970 and 2010 (Ramirez \& Kwak, 2015). With regards to STEM graduates, we detect a sharp decline in Latin America and the Caribbean between 1998 and 2018.

This overview of the literature and arguments leads us to the questions central to our study: (a) What percentage of women graduates obtained STEM degrees, and how does this compare to men graduates with STEM degrees? (b) What percentage of STEM graduates are women relative to men?

\section{Data and Methods}

The data on tertiary graduates by sex, field of study, and country were gathered from the online database of the UNESCO Institute for Statistics. UNESCO uses the International Classification of Education (ISCED) system to categorize higher education institutions by levels and students by field of study, thus categorizing STEM versus non-STEM fields. Three levels of higher education, i.e., higher technical/vocational, undergraduate, and postgraduate, are all included in our analyses as per ISCED's definition of tertiary education (UNESCO, 2012). Additional country level indicators (e.g., level of economic development) were collected from the World Bank (2019). 
The sample includes 143 countries, including territories, throughout the world from 1998 to 2018. UNESCO collects higher education graduation data from national governments around the world on a yearly basis, but not all governments have participated in data collection every year. Countries in the sample vary by level of economic development across different regions. For a complete list of countries included in the sample, see Table 2.1.

\section{Findings}

To answer our first question, we look at the percentage of higher education graduates who obtained STEM degrees. We do so for both women and men. If the acquisition of a STEM degree was unrelated to gender, the percentage for women would be similar to that for men. Quite the contrary - the global average percentage of higher education graduates with STEM degrees is much higher for men throughout this period. In 1998, the percentage for men was 46.98 while it was $21.98 \%$ for women. Twenty years later, the percentage for men had declined to 31.84 and the percentage for women also declined to $13.07 \%$. These common decline patterns add up to and account for why the overall STEM share of higher education graduates has decreased from $34.88 \%$ to $22.44 \%$ in 2018 .

The global pattern of more men than women graduates with STEM degrees is not due to some outlier regions or set of countries. There are regional variations across patterns for both genders, but we find that more men graduate with STEM degrees than women in all regions between 1998 and 2018. As regards the percentage of men graduates with STEM degrees, we find less regional variation in 2018 than in 1998. In 1998, the highest percentage for men was in Latin America at $69.29 \%$, and the lowest was in sub-Saharan Africa at $14.42 \%$. By 2018, however, the percentage of men graduating with STEM degrees across regions converge at around $32 \%$, with the percentages for Latin America and sub-Saharan Africa being 36.49 and 23.01, respectively. With regard to percentage of women graduates with STEM degrees, we also find more regional variation in 1998 than in 2018. The highest percentage of women graduates in STEM fields throughout was found in the Middle East and North Africa, at 21.12 in 1998 and 20.71 in 2018. Sub-Saharan Africa has the lowest percentage of women graduates with STEM degrees throughout, at 9.49 in 1998 and 7.97 in 2018. This suggests that although the rate at which the percentage of STEM graduates is decreasing is higher for men than that for women between 1998 and 2018, higher proportions of men are graduating with STEM degrees than women in all world regions.

To answer our second question, we examine women's share of STEM degree holders, i.e., of STEM graduates, what percentage are women? The global and regional trends in studies that examine women's share in STEM are in the direction of increased women's share of STEM enrollments, from about 10 to $20 \%$ in 1970 to about 30 to $40 \%$ in 2010 (Ramirez \& Kwak, 2015).

What do we find when we shift from enrollments to graduation patterns and extend the trend to 2018? Our main finding is that women's share of STEM degree holders has undergone a modest increase, from 32.5\% in 1998 
Table 2.1 The Complete List of Countries in the Sample, by Income Level

\begin{tabular}{|c|c|c|c|}
\hline High Income & $\begin{array}{l}\text { Upper-Middle } \\
\text { Income }\end{array}$ & $\begin{array}{l}\text { Lower Middle } \\
\text { Income }\end{array}$ & Low Income \\
\hline Andorra & $\begin{array}{l}\text { Antigua and } \\
\text { Barbuda }\end{array}$ & Albania & Angola \\
\hline Aruba & Argentina & Algeria & Armenia \\
\hline Australia & Bahrain & Belarus & Azerbaijan \\
\hline Austria & Barbados & Belize & Bangladesh \\
\hline Belgium & Brazil & Botswana & Benin \\
\hline Bermuda & Chile & Bulgaria & Bosnia and Herzegovina \\
\hline Brunei & Croatia & Cabo Verde & Burkina Faso \\
\hline Canada & Czechia & Colombia & Burundi \\
\hline Cayman Islands & Hungary & Costa Rica & Cambodia \\
\hline Cyprus & Malaysia & Cuba & Cameroon \\
\hline Denmark & Malta & Ecuador & Chad \\
\hline Finland & Mauritius & Egypt & Comoros \\
\hline France & Mexico & El Salvador & Congo \\
\hline Germany & Oman & Estonia & Dem. Rep. of the Congo \\
\hline Greece & Poland & Eswatini & Eritrea \\
\hline Hong Kong & Puerto Rico & Georgia & Ethiopia \\
\hline Iceland & Saudi Arabia & Grenada & Gambia \\
\hline Ireland & Seychelles & Guatemala & Ghana \\
\hline Israel & Slovakia & Indonesia & Guyana \\
\hline Italy & Slovenia & Iran & Honduras \\
\hline Liechtenstein & South Africa & Iraq & India \\
\hline Luxembourg & Uruguay & Jordan & Kenya \\
\hline Macao & & Kazakhstan & Kyrgyzstan \\
\hline Netherlands & & Latvia & Laos \\
\hline New Zealand & & Lebanon & Lesotho \\
\hline Norway & & Lithuania & Madagascar \\
\hline Portugal & & Maldives & Mauritania \\
\hline Qatar & & Morocco & Mongolia \\
\hline Singapore & & Namibia & Mozambique \\
\hline South Korea & & North Korea & Myanmar \\
\hline Spain & & North Macedonia & Niger \\
\hline Sweden & & Palestine & Pakistan \\
\hline Switzerland & & Panama & Rwanda \\
\hline UAE & & Peru & Sri Lanka \\
\hline UK & & Philippines & Sudan \\
\hline \multirow[t]{2}{*}{ USA } & & Romania & Uganda \\
\hline & & Samoa & Vietnam \\
\hline
\end{tabular}


Table 2.1 (Cont.)

\begin{tabular}{|c|c|c|c|}
\hline High Income & $\begin{array}{l}\text { Upper-Middle } \\
\text { Income }\end{array}$ & $\begin{array}{l}\text { Lower Middle } \\
\text { Income }\end{array}$ & Low Income \\
\hline & & Syria & Zimbabwe \\
\hline & & Thailand & \\
\hline & & Tunisia & \\
\hline & & Turkey & \\
\hline & & Ukraine & \\
\hline & & Uzbekistan & \\
\hline & & Venezuela & \\
\hline
\end{tabular}

to $35.2 \%$ in 2018 . Here, too, we see less variation between regions over time. By 2018 , virtually every region is at about $30 \%$ or above but only one is over $40 \%$. Women's share in the Middle East and North Africa is highest at about $45 \%$, and it is lowest in sub-Saharan Africa at just under 30\%. Despite being often seen as the center of scholarship critiquing the lack of women's access to STEM as well as the attention to remedy their lower representation, women's share for North America and Western Europe barely changes over this period, and at slightly over $30 \%$ is comparable to sub-Saharan Africa.

To further probe variation, we examine women's share of STEM graduates across countries by level of economic development, as classified by the World Bank (2019), based on income groups (see Figure 2.1). We do so for each time

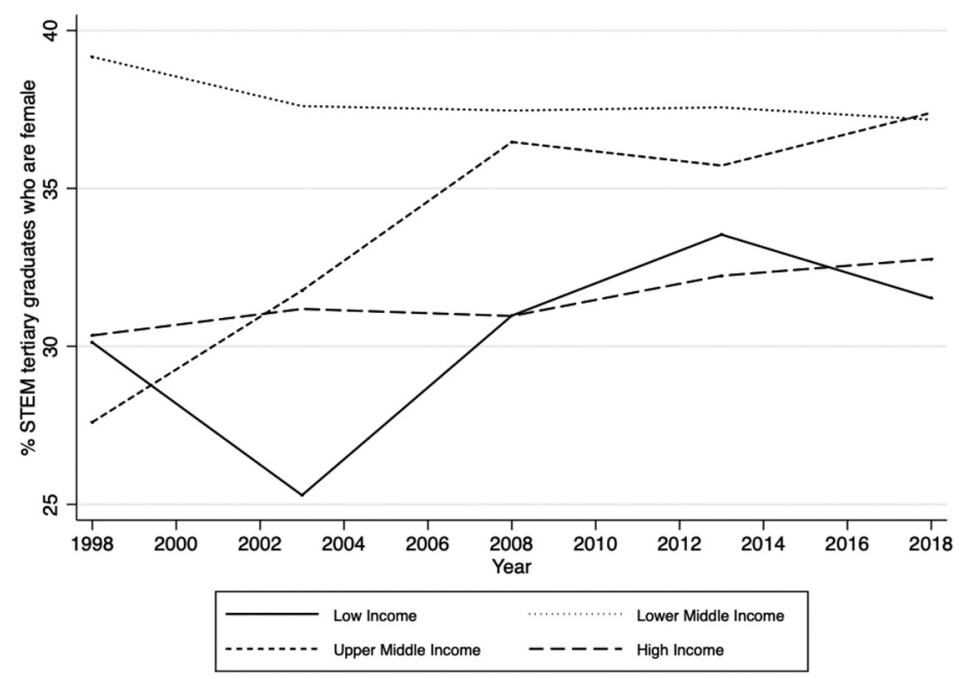

Figure 2.1 Women's share of STEM graduates across countries by level of economic development, as classified by the World Bank (2019). 
point from 1998 to 2018. Since country income levels change over time, we base our analysis on the classification of countries in 1998 across these four categories: high income, upper-middle income, lower-middle income, and low income. We again find less variation in 2018 than in 1998, reflecting increases in three of these economic categories and a modest decline in the upper middle-income group that in 1998 was ahead. By 2018, women's share of STEM graduates is over $35 \%$ in both the upper-income and middle-income groups and below $35 \%$ in both the low- and high-income groups of countries. There appears to be no modernization advantage for women in the top income countries. This finding is consistent with the lack of advantage for the North America and Western Europe region where many of the top income countries find themselves.

To summarize, our exploratory study shows that when one compares higher education graduates with STEM degrees, one finds that men are more likely than women to be STEM graduates. This finding is stable across regions and between 1998 and 2018. However, when the focus is on women's share of STEM graduates, we find a modest increase over time. This increase is not driven by the more developed or more Westernized countries. These developments in women in STEM are taking place in a global context in which feminist scholars and national policy analysts often emphasize the importance of having more women in STEM to meet women's needs and interests but also to foster national economic growth. The global education context, however, is one in which STEM enrollments and graduations are not increasing relative to overall growth in higher education.

In what follows, we seek to make sense of these findings and sketch future lines of inquiry to further our understanding of women graduates and STEM.

\section{Discussion}

At first glance, the answers to our two different but interrelated questions may seem paradoxical. Men graduates are more likely to obtain a degree in STEM, yet women graduate's share of STEM has increased, albeit modestly. This is not as odd as it may seem. The key to understanding these different trends is the realization that the decrease in men graduates with a STEM degree was sharper than that of women graduates. In relative terms, both men and women are opting to graduate with non-STEM degrees. Between 1998 and 2018, this choice pattern is more pronounced for men. The increase in women's share of STEM degrees logically follows. Growth in women's share of STEM degrees is not mainly a function of increased interest and demand for STEM degrees on the part of women. Rather, only relative to men do we see a small increase in women's share of STEM degrees. The absence of an overall surge of interest in STEM degrees in comparison to non-STEM degrees is intriguing. Is this because STEM degrees are harder to obtain? Or, is this due to students making choices not strongly driven by considerations of occupational and earnings payoffs? Frank and Gabler (2006) find that the 
higher education fields of study that grow the most across the world are within the social sciences. Other studies indicate that students, both boys and girls, express less favorable attitudes toward math in the most affluent countries (Charles et al., 2014).

But even more intriguing is why the lack of a surge is more pronounced for men. STEM fields have often been discussed as culturally defined domains for men. That is why these fields are seen as harder to crack for women. STEM as a male-dominated field may be especially the case not only in Western contexts, but also in highly individualist cultures where selection of a field of study is left up to individual tastes, the latter often shaped by sex stereotyping of subject matter. This is the core argument advanced by Charles and Bradley (2009) in making sense of why women veer away from STEM more so in countries with a stronger individualist culture. Charles and Bradley (2009) call the process by which women opt out of STEM as "indulging our gendered selves" (p. 924). Perhaps the globalization of an individualist culture and "changing cultural characteristics" (Aycan \& Fikret-Pasa, 2003, p. 129) result in both men and women self-indulging and making choices more contingent on immediate tastes than on subject matter competence. Perhaps in some societies, it is the study of the humanities, e.g., religion, philosophy, and literature, that is regarded as more appropriate for men while seemingly more mundane subjects like the basic and applied natural sciences are more open to women. The association between STEM and male appropriateness may vary across regions, and that may account for why the Middle East and North Africa region (traditional in some respects) may nevertheless be more open to women in STEM.

In less individualist cultures, selection of a field of study may be more guided by ideas about subject specific competence, perhaps shaped by counseling and/or tracking systems. Offsetting this argument is that some of the less individualist cultures are also characterized by traditional gender role structures that would block women from entry into STEM but also benefit from having younger systems of higher education (and STEM therein) that came about at a time when women had greater rights. Evidence is growing that women fare better in STEM in less economically developed countries as well as in less developed parts of countries (Perez-Felkner et al., 2020). Images of who constitute scientists and engineers are evolving to include women in growing economies (Gupta, 2012 for India and Mellström, 2009 for Malaysia). Yet, labor market segregation remains (Gupta, 2015). Entry into STEM in higher education is easier than entering and remaining in occupations related to STEM (Chow \& Charles, 2019; Jacobs, 1996).

\section{Areas for Future Research and Conclusions}

Our findings show that the story of women in STEM is more nuanced than commonly imagined. Although women are underrepresented in STEM fields globally, women's share of STEM graduates has increased over time, especially in growing economies. In some parts of the world such as the Middle East and North Africa, findings suggest that there actually may be a reverse gender gap 
in higher education although this does not necessarily translate into labor market outcomes. Moreover, it appears that there has not been an upsurge in STEM graduates for both men and women, suggesting that there may be a need to promote STEM pathways to all genders given the importance of STEM fields to fulfill the needs of the future workforce.

Early policy interventions to boost confidence and interest in students and exposing students to real-life experiences and applications in STEM fields, as well as role models in and outside the classroom, can help attract more young people to STEM fields. What is perhaps more important - and a greater policy concern - than increasing the number of women pursuing STEM in higher education, however, is translating higher education outcomes to labor market outcomes. Nonetheless, the reasons why fewer women, especially those in higher income countries, are in STEM fields need to be explored and explained further.

We conclude by recommending several future research directions. First, to get a better longer-term picture, graduation data from earlier eras would be useful. We see from our study that there was more change in the direction of gender equality between 1998 and 2008 than in the last ten years. Was there even greater positive change earlier? Should we think of the last ten years as a temporary stall, or can one imagine another spike in the future? And if so, what societal and global conditions would facilitate further increases?

Second, the "E" in STEM is a domain often more difficult to enter for women. Kwak and Ramirez (2019) find that globally women are less likely to be in engineering fields of study than in the natural sciences. Is this also the case when we examine degree holders rather than enrollments? If engineering is more of a chilly climate for women with regard to enrollments, one would expect a "Siberian impact" with regard to graduations in engineering.

Third, ideas about pipelines often start with access to math and science instruction at lower levels and academic achievements therein (Wiseman, 2008). Exposed to less challenging courses in STEM at the pre-collegiate level often taught in ways that are assessed as male biased (Boaler, 1997), women enter higher education less well prepared and less inclined to major in STEM fields. One could further argue that there may be a gap between enrollment and graduation rates. More directly studying cross-national variation in the gap will shed light on whether some higher education systems are more open with respect to entry but nevertheless obstruct degree completion.

Fourth, higher education students do not merely face curriculum. They also face professors. Cross-national research on women in tenured faculty positions shows fewer tenured women in the natural sciences and engineering (Nakagawa, Wotipka, \& Buckner, 2020). Tracing the relationship between women in positions of authority in STEM (professors, deans, presidents) and women STEM degree holders is a much-needed endeavor.

Lastly, we need more cross-national, qualitative case studies to better understand what likely facilitates and hinders entry into and completion of STEM degrees. These studies should compare women and men over extended periods of time, ideally from secondary schools to higher education and beyond. 


\section{Note}

1 Our data come from the UNESCO Institute for Statistics, which uses the International Classification of Education (ISCED) system to categorize higher education institutions by levels. ISCED levels $5-8$ are included under UNESCO's tertiary education category, which includes short-cycle tertiary education, bachelor's, master's, and doctoral degrees (UNESCO, 2012).

\section{References}

African Union. (2020). Goals \& priority areas of Agenda 2063. https://au.int/agenda 2063/goals

Aycan, Z., \& Fikret-Pasa, S. (2003). Career choices, job selection criteria, and leadership preferences in a transitional nation: The case of Turkey. Fournal of Career Development, 30(2), 129-144.

Baker, D. P., \& Jones, D. P. (1993). Creating gender equality: Cross-national gender stratification and mathematical performance. Sociology of Education, 66(2), 91-103.

Berkovitch, N. (1999). From motherhood to citizenship: Women's rights and international organizations. Johns Hopkins University Press.

Blickenstaff, J. C. (2005). Women and science careers: Leaky pipeline or gender filter? Gender and education, 17(4), 369-386.

Boaler, J. (1997). Reclaiming school mathematics: The girls fight back. Gender and Education, 9(3), 285-305.

Boserup, E. (1981). Population and technological change: A study of long-term trends. Chicago University Press.

Bradley, K. (2000). The incorporation of women into higher education: Paradoxical outcomes. Sociology of Education, 73(1), 1-18.

Bradley, K., \& Ramirez, F. O. (1996). World polity and gender parity: Women's share of higher education, 1965-1985. Research in Sociology of Education and Socialization, 11(1), 63-91.

Charles, M. (2011). What gender is science? Contexts, 10(2), 22-28.

Charles, M., \& Bradley, K. (2009). Indulging our gendered selves? Sex segregation by field of study in 44 countries. American Fournal of Sociology, 114(4), 924-976.

Charles, M., Harr, B., Gech, E., \& Hendley, A. (2014). Who likes math where? Gender differences in eighth-graders' attitudes around the world. International Studies in Sociology of Education, 24(1), 85-112.

Chow, T., \& Charles, M. (2019). An inegalitarian paradox: On the uneven gendering of computing work around the world. In C. Frieze \& J. L. Quesenberry (Eds.), Cracking the digital ceiling: Women in computing around the world (pp. 25-45). Cambridge University Press.

Committee on Prospering in the Global Economy of the 21st Century. (2007). Rising above the gathering storm: Energizing and employing America for a brighter economic future. National Academies Press.

Dorius, S. F., \& Firebaugh, G. (2010). Trends in global gender inequality. Social Forces, 88(5), 1941-1968.

Drori, G. S. (2000). Science education and economic development: Trends, relationships, and research agenda. Studies in Science Education, 35(1), 27-57.

Ellis, J., Fosdick, B. K., \& Rasmusen, C. (2016). Women 1.5 times more likely to leave STEM pipeline after calculus compared to men: Lack of mathematical confidence a potential culprit. PLOS ONE, 11(7), 1-14. 
European Technology Assessment Network. (2000). Science Policies in the European Union: Promoting excellence through mainstreaming gender equality. European Union Publications Office.

Frank, D. J., \& Gabler, J. (2006). Reconstructing the university: Worldwide shifts in academia in the 20th century. Stanford University Press.

Gupta, N. (2012). Women undergraduates in engineering education in India: A study of growing participation. Gender, Technology and Development, 16(2), 153-176.

Gupta, N. (2015). Rethinking the relationship between gender and technology: A study of the Indian example. Work, Employment and Society, 29(4), 661-672.

Hanushek, E. A., \& Kimko, D. D. (2000). Schooling, labor-force quality, and the growth of nations. American Economic Review, 90(5), 1184-1208.

Huyer, S. (2015). Is the gender gap narrowing in science and engineering? (UNESCO Science Report Series 6, Chapter 3). UNESCO. https://en.unesco.org/sites/default/files/ usr15_is_the_gender_gap_narrowing_in_science_and_engineering.pdf

Jacobs, J. A. (1996). Gender inequality and higher education. Annual Review of Sociology, 22, 153-185.

Kelly, G. P. (1989). Achieving equality in education-prospects and realities. In G. P. Kelly (Ed.), International handbook of women's education (pp. 547-569). Greenwood Press.

Kugler, A. D., Tinsley, C. H., \& Ukhaneva, O. (2017). Choice of majors: Are women really different from men? NBER Working Paper No. 23735. National Bureau of Economic Research. https://econpapers.repec.org/paper/nbrnberwo/23735.htm

Kwak, N., \& Ramirez, F. O. (2019). Is engineering harder to crack than science? A cross-national Analysis of women's participation in male-dominated fields of study in higher education. In A. W. Wiseman (Ed.), Annual review of comparative and international education 2018 (pp. 159-183). Emerald Publishing.

Mellström, U. (2009). The intersection of gender, race and cultural boundaries, or why is computer science in Malaysia dominated by women?. Social Studies of Science, 39(6), 885-907.

Nakagawa, M., Wotipka, C. M., \& Buckner, E. (2020). Faculty in globally-ranked universities in comparative perspective: Differences by gender, fields, and tenure status. [Unpublished manuscript]. Stanford University.

National Commission on Excellence in Education. (1983). A nation at risk: The imperative for educational reform. The Elementary School fournal, 84(2), 113-130.

Perez-Felkner, L., Felkner, J. S., Nix, S., \& Magalhães, M. (2020). The puzzling relationship between international development and gender equity: The case of STEM postsecondary education in Cambodia. International Fournal of Educational Development, 72, pp. 1-11.

Ramirez, F. O., \& Kwak, N. (2015). Women's enrollments in STEM in higher education: Cross-national trends, 1970-2010. In W. Pearson, L. Frehill, \& C. McNeely (Eds.), Advancing women in science (pp. 9-49). Springer.

Ramirez, F. O., \& Lee, M. (1995). Education, science, and economic development. In G. A. Postiliogne \& W. O. Lee (Eds.), Social change and educational development in Mainland China, Taiwan, and Hong Kong (pp. 15-39). University of Hong Kong, Center for Asian Studies.

Ramirez, F. O., \& Wotipka, C. M. (2001). Slowly but surely? The global expansion of women's participation in science and engineering fields of study, 1972-92. Sociology of Education, 74(3), 231-251.

Ramirez, F. O., Luo, X., Schofer, E., \& Meyer, J. W. (2006). Student achievement and national economic growth. American Fournal of Education, 113(1), 1-29.

Ramirez, F. O., Soysal, Y., \& Shanahan, S. (1997). The changing logic of political citizenship: Cross-national acquisition of women's suffrage rights, 1890 to 1990. American Sociological Review, 62(5), 735-745. 


\section{Seungah S. Lee et al.}

Ritz, J. M., \& Fan, S. (2015). STEM and technology education: International state-ofthe-art. International Fournal of Technology and Design Education, 25(4), 429-451.

Schofer, E., \& Meyer, J. W. (2005). The worldwide expansion of higher education in the twentieth century. American Sociological Review, 70(6), 898-920.

Schofer, E., Ramirez, F. O., \& Meyer, J. W. (2000). The effects of science on national economic development, 1970 to 1990. American Sociological Review, 65(6), 866-887.

Shapiro, C. A., \& Sax, L. J. (2011). Major selection and persistence for women in STEM. New Directions for Institutional Research, 2011(152), 5-18.

UNESCO. (2012). International standard classification of education ISCED 2011. United Nations International Family of Economic and Social Classifications, UNESCO Institute for Statistics.

Vest, G. M. (2010). Rising above the gathering storm revisited: Rapidly approaching category 5. National Academy of Sciences.

Wiseman, A. W. (2008). A culture of (in)equality?: A cross-national study of gender parity and gender segregation in national school systems. Research in Comparative and International Education, 3, 179-201.

World Bank. (2019). Historic classification by income [Data file]. https://datahelpdesk. worldbank.org/knowledgebase/articles/906519-world-bank-country-and-lending-groups

Wotipka, C. M., \& Ramirez, F. O. (2003). Women in science: For development, for human rights, for themselves. In G. S. Drori, J. W. Meyer, F. O. Ramirez, \& E. Schofer (Eds.), Science in the modern world polity: Institutionalization and globalization (pp. 174-195). Stanford University Press.

Zou'bi, M. R., Mohamed-Nour, S., El-Kharraz, J., \& Hassan, N. (2015). The Arab States. (UNESCO Science Report Series 6, Chapter 17). UNESCO. https://en. unesco.org/sites/default/files/usr15_the_arab_states.pdf 